\title{
Efeito da solarização e do brometo de metila sobre a comunidade de fungos do solo
}

\author{
Wilson Story Venâncio ${ }^{1, *}$, César Júnior Bueno ${ }^{2}$, Nilton Luiz de Souza ${ }^{3}$
}

${ }^{1}$ UEPG, Curso de Agronomia, Depto. de Fitotecnia e Fitossanidade, CP 992/3, 84.010-130, Ponta Grossa/PR, Brasil; ${ }^{2}$ Apta Regional do Extremo Oeste, Araçatuba/SP; ${ }^{3}$ Faculdade de Ciências Agronômicas - Unesp, Botucatu/SP e bolsista do CNPq.

*Parte da dissertação de mestrado do primeiro autor.

Autor(a) para correspondência: Wilson Story Venâncio.

Data de chegada: 29/07/2004. Aceito para publicação em: 30/06/2005.

\begin{abstract}
Venâncio, W.S.; Bueno, C.J.; Souza, N. L. Effect of soil solarization and methyl bromide on the soil fungi community. Summa Phytopathologica, v.32, n.2, p.183-185, 2006.

Soil microbial community is of great importance for the crop development. However, the methods of control, chemical (methyl bromide) and physical (soil solarization), change such community. The present work aimed to study the behaviour of the community of fungi in solarized and fumigated (methyl bromide) soils. The experimental design was randomized in complete blocks, with 3 treatments (soil solarization, methyl bromide, and control) and 7 replications. The soil fungi community was evaluated in both, a quantitative and qualitative way during 3 periods (before, during and after solarization) through soil samples collected from 3 depths $(0-5 ; 10-15$, and 20-25 cm). During soil

solarization, a reduction of the soil fungi community, quantitatively, occurred in all layers evaluated. However, the decrease was more significant in the superficial layer. Soil solarization also reduced the number of different species of fungi, qualitatively, but in the layer of $20-25 \mathrm{~cm}$ the decrease was to zero after 56 days of evaluation. The soil microbial re-colonization was quantitatively larger for the treatment with methyl bromide by comparing to the other treatments. However, qualitatively, the increase was not the same. The increase of the soil microbial recolonization in the solarized and control treatments was accompanied by diversification of fungal species.
\end{abstract}

Additional keywords: Microbial re-colonization, physical control and chemical control.

\section{RESUMO}

Venâncio, W.S.; Bueno, C.J.; Souza, N. L. Efeito da solarização e do brometo de metila sobre a comunidade de fungos do solo. Summa Phytopathologica, v.32, n.2, p.183-185, 2006.

A microbiota do solo é de grande importância no desenvolvimento de culturas. Os métodos de controle, químico (brometo de metila) e físico (solarização), alteram essa microbiota. O presente trabalho objetivou estudar o comportamento da comunidade de fungos em solo solarizado e fumigado (brometo de metila). O delineamento experimental foi de blocos ao acaso, com três tratamentos (solarização, brometo de metila e testemunha) e sete repetições. A comunidade de fungos do solo foi avaliada de forma quantitativa e qualitativa, em três momentos (antes, durante e após a solarização) com amostras coletadas de três profundidades $(0-5 ; 10-15$ e $20-25$ $\mathrm{cm})$. Durante a solarização ocorreu uma redução na comunidade de fungos do solo, em termos quantitativos, em todas as camadas amostradas. No entanto, essa diminuição foi mais significativa na camada superficial $(0-5 \mathrm{~cm})$. Em termos qualitativos, a solarização reduziu também o número de diferentes espécies de fungos do solo, mas na camada de 20-25 cm, essa diminuição foi a zero aos 56 dias de avaliação. A recolonização da microbiota do solo, em termos quantitativos, foi maior no tratamento com brometo de metila do que nos demais. Entretanto, esse aumento não foi o mesmo em termos qualitativos. Nos tratamentos solarizado e testemunha, o aumento na comunidade de fungos do solo foi acompanhado pela diversificação de espécies fúngicas.

Palavras-chave adicionais: Recolonização microbiana, controle físico e controle químico.

A microbiota natural do solo é de grande importância no desenvolvimento de culturas, principalmente em regiões de agricultura intensiva. Inúmeros métodos de controle tais como o químico (brometo de metila) e o físico (solarização do solo) podem causar alterações quantitativas e qualitativas nessa microbiota $(1,5,7)$.

O presente trabalho objetivou estudar o comportamento da comunidade de fungos em solo solarizado e fumigado (brometo 
de metila).

O ensaio foi realizado na Faculdade de Ciências Agronômicas da UNESP de Botucatu/SP, no período de 22/11/1989 a 17/ 01/1990, proporcionando 56 dias de solarização. O delineamento experimental foi de blocos ao acaso, com três tratamentos (solarização, brometo de metila e testemunha) e sete repetições. As parcelas possuíram dimensões de 1,60 x 4,00 m e o espaçamento entre elas foi de $1,0 \mathrm{~m}$. No tratamento solarizado, utilizou-se o filme de polietileno aditivado de $35 \mu \mathrm{m}$ de espessura. Dois dias antes de terminar a solarização, utilizou-se no tratamento com brometo de metila a aplicação de $393 \mathrm{cc}$ de brometo por parcela $\left(106,25 \mathrm{~g} / \mathrm{m}^{2}\right)$ e, em seguida, cobriu-se com plástico por 72 horas. Os parâmetros avaliados foram a comunidade de fungos do solo, de forma quantitativa e qualitativa, em três momentos (antes, durante e após a solarização). Durante os tratamentos, a avaliação foi semanal até completar 56 dias. Já após a aplicação dos tratamentos, o monitoramento ocorreu a cada 14 dias até completar também 56 dias. Amostras de 113,90 cc de solo foram coletadas, ao acaso, de três profundidades (0-5; 5-10 e 10-15 $\mathrm{cm}$ ), em parcelas pré-determinadas. O método utilizado para avaliar de forma quantitativa a comunidade de fungos do solo foi o de Warcup (8), que consistiu em efetuar diluições seriadas de amostra do solo seguido de plaqueamento de alíquotas em meio de Martim modificado (3). Para cada diluição foram feitas três repetições. A avaliação foi expressa em unidades formadoras de colônia (ufc) por grama de solo seco. No método qualitativo, efetuou-se comparação morfológica com uma coleção de diferentes espécies de fungos previamente isoladas do solo amostrado. A avaliação foi expressa em número de diferentes espécies fúngicas.

Durante a solarização ocorreu uma redução na comunidade inicial de fungos do solo, em termos quantitativos, em todas as camadas amostradas. No entanto, essa diminuição foi mais significativa na camada superficial $(0-5 \mathrm{~cm})$ do que nas demais (Figura 1A). Estes dados corroboram com os relatos de Souza (6), que descreveu também uma diminuição na microbiota em solos solarizados. Segundo Katan et al. (2), um aumento de aproximadamente $10^{\circ} \mathrm{C}$ nas camadas superiores é suficiente para eliminar alguns patógenos, quer pelo efeito direto da temperatura quer pelo efeito cumulativo de temperatura subletais, selecionando os organismos antagonistas. A solarização reduziu também a diversificação de espécies fúngicas no solo nas camadas amostradas. No entanto, essa diminuição foi a zero aos 56 dias de tratamento na camada de $20-25 \mathrm{~cm}$ de profundidade (Figura 1B).

Uma redução nas diferentes populações de fungos do solo, em termos quantitativos, foi observada no tratamento com brometo de metila no período de 0 a 14 dias de avaliação nas camadas amostradas (Figura 2A). De acordo com French \& Hebert (1), o brometo de metila controla quase todos os organismos vivos quando aplicado ao solo. Após os 14 dias de tratamento, houve um aumento significativo no número da comunidade recolonizadora de fungos do solo e esse crescimento ocorreu de forma igual em todas as camadas (Figura 2A). Munnecke (5) constatou que em solos fumigados pode ocorrer reinfestação por fitopatógenos, devido à alteração na microbiota do solo. Após a solarização, constatou-se neste tratamento um número baixo de comunidade de fungos na camada superficial. No entanto, nas demais camadas amostradas, observou-se um aumento significativo e de forma equânime nessa comunidade recoloni-

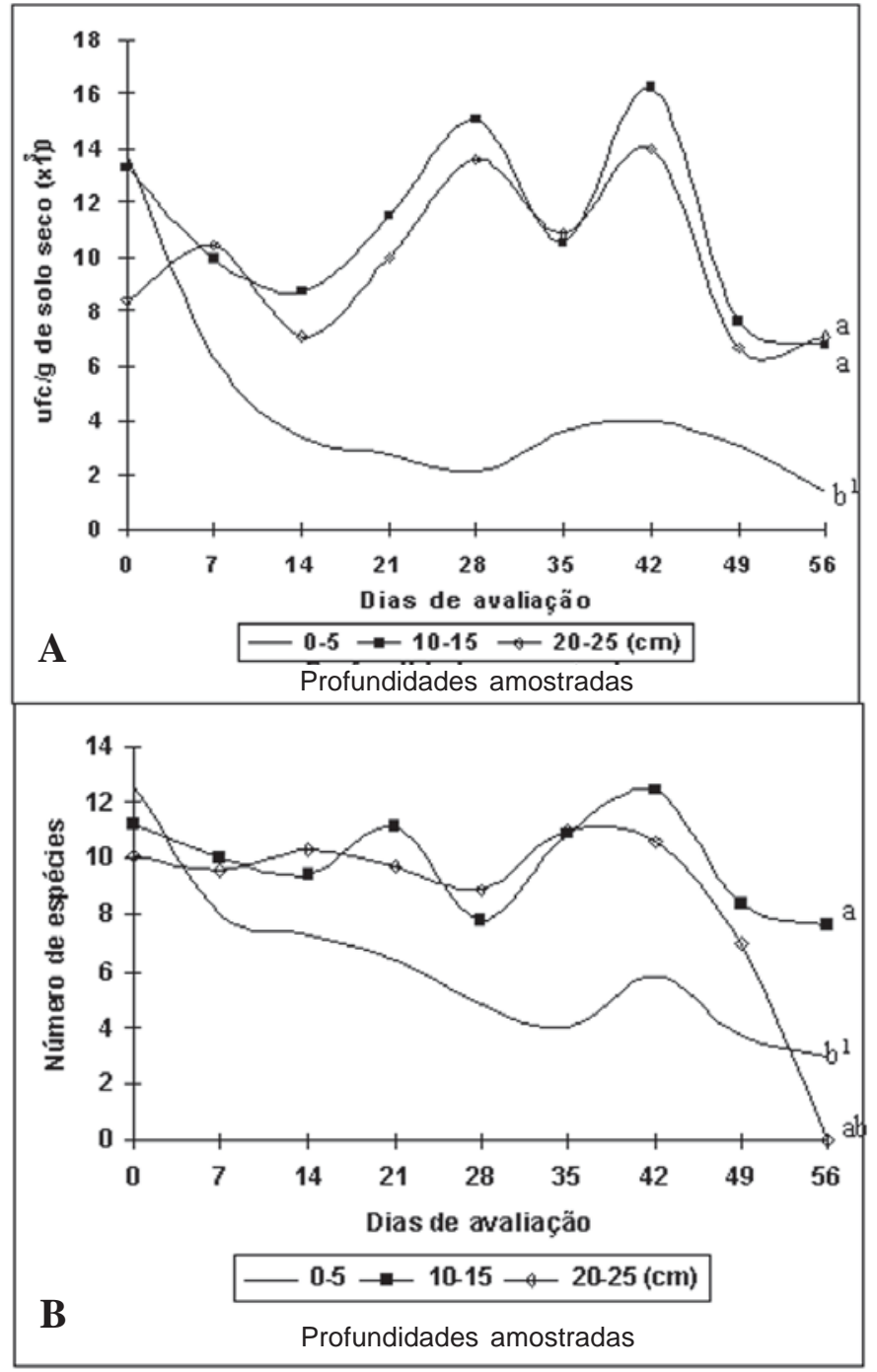

Figura 1. Avaliação quantitativa (A) e qualitativa (B) da comunidade de fungos, amostrada em três profundidades do solo, durante o tratamento de solarização.

${ }^{1}$ Mesmas letras não diferem estatisticamente pelo teste de Tukey a $5 \%$ de probabilidade quanto as profundidades amostradas.

zadora (Figura 2A). Stapleton (7) relatou que após a solarização ocorre um "vácuo biológico" parcial no solo. O substrato disponível tende a ser utilizado pelos antagonistas (Bacillus spp., Pseudomonas fluorescens, etc), que passam a serem prevalentes e suprimem a recolonização por fitopatógenos. No tratamento testemunha, verificou-se, quantitativamente, uma mesma microbiota do solo nas camadas amostradas (Figura 2A). Analisando todos os tratamentos e todos os dias de amostragem, pode-se concluir que o tratamento com brometo de metila diferiu significativamente dos demais, enquanto que o tratamento solarizado e testemunha não diferiram entre si (Figura 2A).

No tratamento com brometo de metila, constatou-se um baixo número de espécies fúngicas reinfestantes, sendo esse número estatisticamente igual para as três camadas (Figura 2B). Essa observação, corrobora com os dados do trabalho de Millhouse \& Munneck (4), que descreveram a presença de poucas espéci- 
es de fungos e bactérias em solos fumigados quando comparados com os não tratados. No trabalho de Milhouse \& Munnecke (4), Trichoderma spp. e Penicillium spp. predominaram na nova composição da microbiota. Após a solarização, verificouse neste tratamento um pequeno número de espécies fúngicas reinfestantes na camada superficial (Figura 2B). Nas demais, houve um aumento significativo nessa comunidade. Essa diversidade populacional de fungos do solo explica a ocorrência da indução de supressividade em solos solarizados. No tratamento testemunha, constatou-se um aumento qualitativo e significativo na comunidade de fungos do solo, sendo esse aumento igual para as três camadas (Figura 2B). Analisando todos os tratamentos e todos os dias de amostragem, pode-se concluir que o tratamento com brometo de metila diferiu significativamente dos demais, enquanto que o tratamento solarizado e testemunha não diferiram entre si (Figura 2B).

Durante a solarização ocorre uma redução na microbiota do solo, mas após a aplicação da técnica, observa-se um aumento quantitativo e qualitativo na comunidade fúngica. Este fato, explica a baixa reinfestação de fitopatógenos em solos solarizados.

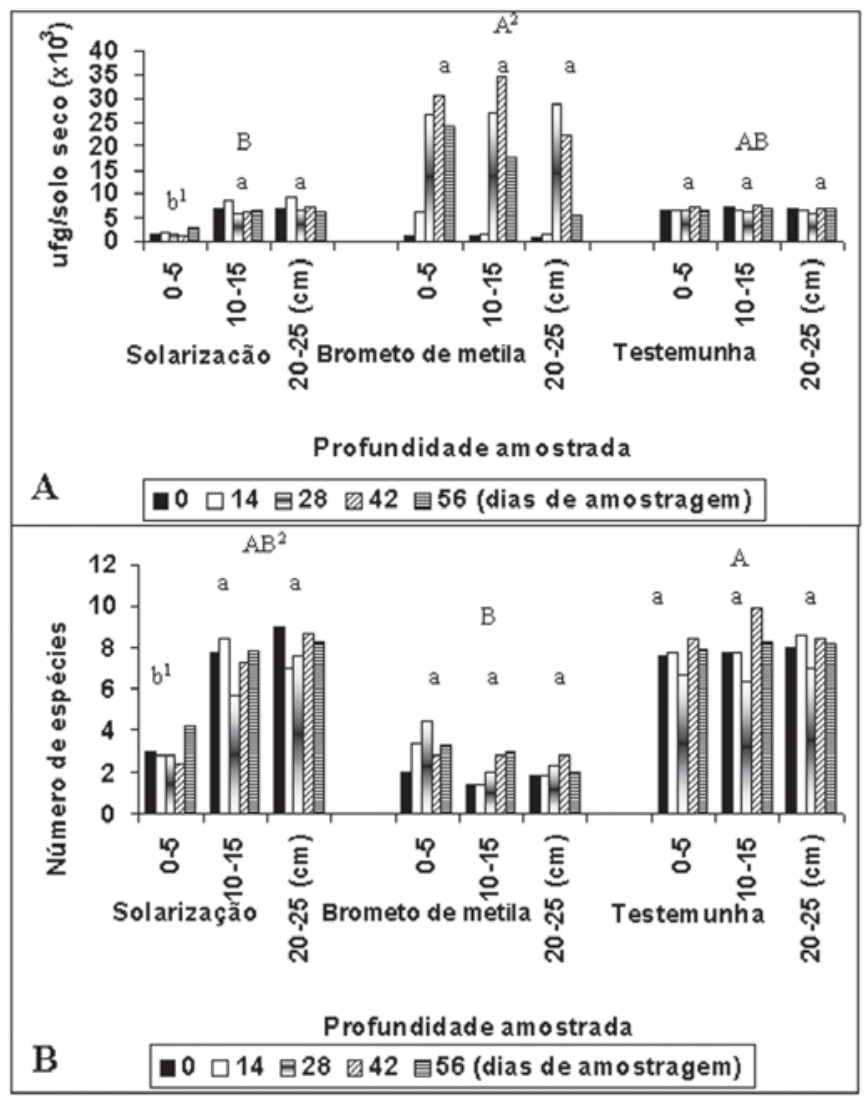

Figura 2. Avaliação quantitativa (A) e qualitativa (B) da comunidade de fungos, amostrada em três profundidades do solo, após a aplicação dos diferentes tratamentos.

${ }^{1,2}$ Mesmas letras não diferem estatisticamente pelo teste de Tukey a $5 \%$ de probabilidade, analisando quanto as profundidades amostradas por tratamento (letra minúscula) e comparação entre os tratamentos pela média de todas as profundidades (letra maiúscula).

\section{REFERÊNCIAS BIBLIOGRÁFICAS}

1. French, E.R.; Hebert, T.T. Métodos de investigacion fitopatológica. San José: Editorial IICA, 1980. 289p.

2. Katan, J.; Greenberger, A.; Alon, H.; Grinstein, A. Solar heating by polyethylene mulching for the control of diseases caused by soilborne pathogens. Phytopathology, St. Paul, v.66, n.5, p.683688, 1976.

3. Martin, J.P. Use of acid, rose bengal and streptomycin in the plate method for estimating soil fungi. Soil Science., Baltimores, v.69, n.3, p.215-232, 1950.

4. Millhouse, D.E.; Munnecke, D.E. Effects of methyl bromide dosage on microorganisms in soil before and after growth of Nicotiana glutinosa. Phytopathology, St. Paul, v.71, n.4, p.418421, 1981.

5. Munnecke, D.E. Methyl bromide for control of soilborne fungal pathogens. In: International Citrus Congress, 2., 1977, Orlando. Proceedings. Orlando: International Society of Citriculture, 1977. v. 3, p. 853-856.

6. Souza, N.L. Soil solarization. Summa Phytopathologica, Jaguaiuna, v.20, n.1, p.3-15, 1994.

7. Stapleton, J.J. Thermal inactivation of crop pests and pathogens and other soil changes caused by solarization. In: International Conference of Soil Solarization, 1., 1990, Ammam. Proceedings. Rome: DAO, 1991. p.37-47.

8. Warcup, J.H. Methods for isolation and estimation of activity of fungi in soil. In: Parkinson, D.; Waid, J.S. The ecology of soil fungi. Liverpool: Liverpool University Press, 1960. p.3-21. 